\title{
O DIREITO EM UMA TEORIA DA JUSTIÇA DE RAWLS
}

\author{
Delamar José Volpato Dutra \\ Universidade Federal de Santa Catarina/CNPq
}

Marcos Rohling

Universidade Federal de Santa Catarina

ABSTRACT: Rawls's work is responsible for the rehabilitation and strengthening of political and moral philosophy. However, there is clearly, as some critics claim, a certain deficit regarding the treatment of the law. With that in mind, this article presents a discussion on the law in A Theory of Justice, particularly with regard to the legal system and its related concepts. So we discuss the concepts of formal justice and rule of law, aimed at protecting basic freedoms.

KEYWORDS: legal system, rule of law, formal justice, Rawls.

RESUMO: A obra de Rawls é responsável pela reabilitação e revigoramento da filosofia política e da filosofia moral. Todavia, existe visivelmente, como alguns críticos afirmam, um certo déficit quanto ao tratamento dado ao direito. À luz disso, neste artigo, apresenta-se uma discussão sobre o direito em Uma Teoria da Justiça, principalmente no tocante ao sistema jurídico e seus conceitos correlatos. Assim, abordam-se os conceitos de justiça formal e estado de direito, tendo em vista a proteção das liberdades básicas.

PALAVRAS-CHAVE: sistema jurídico, estado de direito, justiça formal, Rawls. 


\title{
Introdução
}

\author{
"Na verdade, constatamos que a \\ exigência geral de igualdade jamais consiste \\ noutra coisa que numa rejeição de certas \\ desigualdades concretas, e não de todas as \\ desigualdades imagináveis."1
}

$\mathrm{Na}$ filosofia do direito contemporânea pode-se afirmar que a duradoura autoridade do positivismo jurídico sofreu forte abalo, fato este que fez com que filósofos e juristas se preocupassem com a crise de racionalidade que daí deriva. Embora não exista certa unidade em relação à definição desta nova realidade, ela vem sendo denominada de póspositivismo, tendo em conta sustentar uma "conexão necessária entre o direito e a moral, a qual penetraria no ordenamento jurídico, através da Constituição, especialmente, a partir dos direitos fundamentais." ${ }^{2}$ Neste prisma, temas como a justiça, moral, legitimidade, definição e papel do direito passaram a ser identificados como temas cruciais no universo da filosofia do direito, os quais estão presentes nas obras de filósofos como Habermas, Dworkin, Alexy, Ely e Rawls, entre outros. É precisamente sobre a definição de direito e seu papel em Rawls que essa investigação se ocupa.

Rawls não era jurista e nem mantinha qualquer vínculo especial com o Direito, como é o caso de Dworkin, por exemplo, que é um egresso das fileiras do direito. Contudo, conforme se tome a acepção da expressão filosofia do direito, pode-se aferir e assumir a posição de que Rawls produziu uma extensa obra de importância capital à filosofia do direito sendo, por conseguinte, admissível a acepção de ser ele um filósofo do direito. Esse entendimento se sustenta na afinidade das variadas preocupações que o autor teve em sua teoria da justice as fairness com as que costumam ser vinculadas à filosofia do direito. A este propósito é válido afirmar que no âmbito da filosofia do direito a obra de Rawls tem alavancado sérios estudos, a tal ponto que Dworkin chega a afirmar que $A$ Theory of Justice 3 não pode ser

\footnotetext{
${ }^{1}$ Cf. PERELMAN, Ética e Direito, 216.

2 Cf. LOIS, prefácio, In: DUTRA, Manual de Filosofia do Direito, p. 10.

3 Doravante utilizar-se-á a abreviatura TJ para A Theory of Justice, Cambridge: Harvard University Press, 1971. [trad. bras: Almiro Piseta e Lenita M. R. Esteves. São Paulo: Martins Fontes, 2002.]
} 
ignorada por nenhum constitucionalista. ${ }^{4}$ No que tange a esta questão, podese afirmar que:

\begin{abstract}
A obra de Rawls, juntamente com a de Dworkin [...], determina uma virada na concepção de direito, deslocando o seu entendimento da vertente positivista de Kelsen, Austin e Hart, bem como da vertente utilitarista de Bentham e Mill, para uma concepção que, em última análise, recupera as imbricações entre direito e moral. ${ }^{5}$
\end{abstract}

Ademais, a linguagem em que a filosofia de Rawls foi traduzida, assim como a de outros filósofos políticos, entre os quais, Habermas e Dworkin, é a linguagem jurídica, pois, como afirma Lopes,

[...] em sociedades modernas, complexas e organizadas sob as formas políticas atualmente conhecidas, a linguagem na qual os arranjos políticos se expressam e mesmo se concretizam é a linguagem do direito. Discutir princípios de justiça é discutir arranjos políticos, mas arranjos políticos fazem-se sob a linguagem do direito: distribuição de direitos, individuais, civis, políticos, sociais. ${ }^{6}$

Assim, quando se fala das instituições básicas da sociedade, fala-se, em grande medida, numa estrutura amplamente marcada pela influência jurídica. Por conseguinte, tomar-se-á a ideia de que, no pensamento de Rawls, como faz Dworkin ao entendê-lo como um filósofo do direito ${ }^{7}$, mas, principalmente em TJ, existem elementos que podem configurar uma filosofia do direito, pois suas principais contribuições à filosofia jurídica foram dadas por meio de sua filosofia política tendo em vista a teoria jurídica poder ser considerada um segmento da filosofia política.

\footnotetext{
${ }^{4}$ Cf. DWORKIN, Levando os Direitos à Sério, p. 232.

${ }^{5}$ Cf. DUTRA, op. cit.,p. 16.

${ }^{6}$ Cf. LOPES, Prefácio: Justiça e Direito, 13, In: JESUS, John Rawls - A Concepção de Ser Humano e a Fundamentação dos Direitos do Homem.

7 Dworkin, num artigo intitulado Rawls and Law, por ocasião de um simpósio sobre a obra de Rawls e 0 Direito - mais tarde recolhido na obra Justice in Robes -, afirmou que Rawls pode ser visto como um filósofo do direito, pois a filosofia do direito é um segmento da filosofia política, e Rawls versou sobre esta como um todo. Uma vez que seja assim, existem pontos em sua obra que tocam seriamente em questões próprias à filosofia do direito. Cf. DWORKIN, Justice in Robes, 241-62.
} 


\section{A Teoria da Justiça como Equidade}

Conforme alvitra Peres Bermejo, uma teoria do direito precisa considerar os princípios de justiça básicos do ordenamento jurídico ou fontes de legitimidade do sistema. Precisa especialmente, de modo igual, de uma teoria moral que ilumine e justifique esses princípios. ${ }^{8}$ Convém, acerca disso, fazer uma observação. A teoria do direito diferencia-se da filosofia do direito por estabelecer uma consideração do direito completamente separada da filosofia enfatizando-se o caráter eficaz e coercitivo do mesmo, isto é, a teoria do direito toma como ponto de partida a existência do direito positivado buscando a construção de um sistema coerente. ${ }^{9}$

$\mathrm{Na}$ filosofia de Rawls, entretanto, tendo em vista a contiguidade temática com a filosofia do direito, não se procura a avaliação do direito independente do universo filosófico, como fariam a teoria do direito ou a sociologia do direito, mas se procura considerar os princípios que confeririam legitimidade ao sistema jurídico, pertencente à estrutura básica da sociedade ${ }^{10}$ Esses princípios norteadores da ordem jurídica, em função da filiação à tradicional doutrina do contrato social, seriam os princípios da justiça. Dentro desse quadro, é essencial perguntar-se por qual tipo de teoria moral Rawls considera como sendo a perspectiva correta para justificar princípios de justiça.

Obviamente, da leitura de $T J$ e mesmo de artigos anteriores à obra magna, observa-se que, dentre todas as possíveis vias de justificação apontadas pela tradição filosófica, Rawls rechaça teorizações dogmáticas, que ancoram os princípios da justiça numa lei derivada da divindade, em ordens de valores a priori, esquemas intuicionistas ou referências à lei natural. Rawls desenvolve outra perspectiva que é o aprimoramento de elementos já

\footnotetext{
${ }^{8}$ Cf. PERES BERMEJO, Contrato Social y Obediencia al Derecho en el pensamiento de John Rawls, 11. ${ }^{9}$ Cf. DUTRA, op. cit., 17-8. Ver também: ALEXY, The nature of legal philosophy, 161.

10 Segundo Lois, "entende-se por estrutura básica da sociedade o modo pelo qual são distribuídos direitos e liberdades fundamentais dos indivíduos e pelo qual se determina, ainda, a divisão das vantagens da cidadania em termos de renda e riqueza. A estrutura básica compõe-se das principais estruturas jurídicas e sociais (a Constituição e os principais acordos econômicos) e pode, portanto, referir-se à liberdade política em geral ou ao modelo econômico e social específico de cada sociedade." Cf. LOIS, Uma Teoria da Constituição (Tese de doutoramento), 183.
} 
presentes em Outline of a Decision Procedure for Ethics, de $1951 .{ }^{11}$ A justice as fairness, expressão que define a teoria da justiça de Rawls para a escolha de princípios de justiça, advoga uma solução contratualista, através da qual os termos da cooperação social são estabelecidos por pessoas livres e iguais comprometidas por um esquema de cooperação, naquilo que o autor define como posição original, em que as partes estariam sob o véu da ignorância.

A teoria da justiça como equidade é, então, visivelmente uma teoria contratualista, ainda que limitadamente contratualista, segundo ajuíza Rawls, pois que o autor não persegue a dedução de um sistema ético exaustivo, nem tampouco, ambiciona primordialmente a instituição de uma determinada forma de governo, como pretendiam os contratualistas clássicos. ${ }^{12}$ No caso de Rawls, o contrato se aficciona para a eleição de princípios de justiça, os quais constituirão a base para justificar as instituições públicas, entre as quais, pode-se aferir a do direito, e fundamentar os deveres e as obrigações dos cidadãos, entre os quais os de obediência ao direito.

Com efeito, o contratualismo de Rawls é significativamente distinto do contratualismo moderno. Desse modo, como bem salienta Merquior, a natureza do empreendimento de Rawls de reabilitar o contratualismo, alçando-o à posição de alternativa ao utilitarismo, mostrou-se num plano processual, "pois foi nas técnicas que empregou para deduzir princípios de justiça que Rawls adotou uma posição contratualista."13 Rawls não teve a pretensão de justificar o estabelecimento do contrato a partir de uma circunstância historicamente precisável, mas desenvolver um artifício mental que permitisse deduzir princípios de justiça. Desse modo, o contrato social preterido por Rawls

[...] era um contrato social muito diverso do contrato social da primeira tradição moderna, já que seu propósito não consistia no estabelecimento de autoridade e obrigação

\footnotetext{
11 Neste artigo, Rawls desenvolve uma compreensão da ética como sendo uma disciplina que pode aportar uma solução razoável aos conflitos interpessoais baseados em interesses confrontados. Assim, um dos primeiros objetivos deste artigo de Rawls é a busca de critérios razoáveis, isto é, não arbitrários, que possam servir para justificar decisões morais tal como se expressam nos juízos morais ordinários. Cf. RAWLS, Outline of a Decision Procedure for Ethics. In: Collected Papers.

${ }^{12}$ Cf. RAWLS, TJ, §3, 12-3. Ver, também, a última obra publicada de Rawls, sobre as teorias políticas clássicas do pensamento moderno: RAWLS, Lectures of Hitorical Political Philosophical, 2007.

${ }^{13} \mathrm{Cf}$. MERQUIOR, O Liberalismo Antigo e Moderno, 206.
} 
legítimas, como em Hobbes, Locke ou Rousseau, mas em firmar regras de justiça. ${ }^{14}$

No contratualismo ${ }^{15}$ de Rawls ganha requinte o artifício da posição original do qual o filósofo americano deriva os princípios da justiça como equidade. Neste artifício, conforme justifica Freeman, Rawls combina elementos tanto da teoria do direito natural, de herança lockiana, como da teoria hobbesiana do contrato social. ${ }^{16}$ Tratam-se de princípios de justiça que se aplicam, especialmente, mas não exclusivamente, às instituições elementares da estrutura básica da sociedade, pois, por meio dela, dá-se a distribuição de direitos e deveres, bem como a governo da repartição dos benefícios e encargos oriundos da cooperação social. Em TJ, a formulação definitiva reza assim:

1 ${ }^{\text {a }}$ Cada pessoa deve ter o direito igual ao mais abrangente sistema total de liberdades básicas iguais que seja compatível com um sistema semelhante de liberdade para todos.

$2^{\underline{a}}$ As desigualdades econômicas e sociais devem ser ordenadas de tal modo que, ao mesmo tempo:

(a) tragam o maior benefício possível para os menos favorecidos, obedecendo às restrições do princípio da poupança justa, e

(b) sejam vinculadas a cargos e posições abertos a todos em condições de igualdade eqüitativa de oportunidades. ${ }^{17}$

Esses princípios, contudo, ainda encontram-se demasiadamente abstratos. É a sequência de quatro estágios que dará corpo aos princípios de justiça, como observam Kukathas e Pettit, pois aí se evidenciam certas instituição ou práticas deles decorrentes, dentre as quais algumas das principais instituições jurídicas. ${ }^{18}$ Ademais, a seqüência de quatro estágios é um meio para

\footnotetext{
${ }^{14}$ Cf. MERQUIOR, op. cit., 206.

15 Rawls manifesta do seguinte modo, em $T J$, no tocante ao seu desejo, o mérito da terminologia contratualista: "O mérito da terminologia do contrato é que ela transmite a idéia de que princípios da justiça podem ser concebidos como princípios que seriam escolhidos por pessoas racionais e que assim as concepções da justiça podem ser explicadas e justificadas. A teoria da justiça é uma parte, talvez a mais significante, da teoria da escolha racional." Cf. RAWLS, TJ, §3, 18.

${ }^{16} \mathrm{Cf}$. FREEMAN, RAWLS, 14-6.

${ }^{17} \mathrm{Cf}$. RAWLS, TJ, §46, 333-4.

${ }^{18}$ Cf. KUKATHAS \& PETTIT, Rawls: Uma Teoria da Justiça e os seus críticos, 65.
} 
saber em que grau a constituição e as leis existentes são compatíveis ou não com os princípios de justiça inicialmente acordados, tendo em conta sua aplicação, assim como permite oferecer uma base para justificação, argumentação e crítica, numa sociedade democrática, que é a sociedade bemordenada. Sinteticamente, os estágios do processo para a aplicação dos princípios da justiça, podem ser apresentados do seguinte modo:

$1^{\text {a }}$ Estágio: posição original e escolha dos princípios da justiça;

$2^{\text {a }}$ Estágio: convenção constituinte e elaboração de uma constituição justa;

$3^{\text {a }}$ Estágio: legislatura e elaboração de uma legislação justa;

4a Estágio: aplicação das regras a casos particulares pelo executivo e judiciário.

Assim, o esquema de uma sequência de quatro estágios conduz a explicitação da constituição política e das organizações econômicas justas, pois, de acordo com Kukathas e Pettit,

[...] leva Rawls a abordar a questão da natureza da vinculação das pessoas ao mundo imperfeito exterior à $\mathrm{PO}$, ao conformarem-se com as leis de uma sociedade imperfeitamente justa. Para tornar clara a ligação existente entre os princípios de justiça escolhidos na PO e instituições justas, Rawls convida-nos a imaginarmos uma sequência de quatro estágios: na primeira etapa, na $\mathrm{PO}$, os princípios são escolhidos, após o que as partes na PO se reúnem numa assembleia constituinte, na qual decidem sobre a justiça das formas políticas e escolhem uma constituição. Esta é a segunda etapa, em que se estabelecem claramente os direitos e liberdades fundamentais. A partir de então é possível legislar fazer leis que dizem respeito à estrutura econômica e social da sociedade: é a terceira etapa, em que se trata da justiça das leis e das políticas econômicas e sociais. Quando esta se completa, já nos resta, na quarta etapa, a aplicação das regras pelos juízes e outras autoridades. ${ }^{19}$

${ }^{19}$ Cf. KUKATHAS \& PETTIT, op. cit., 65. 
Uma vez desenvolvida a sequência de quatro estágios, que servirá de avaliação acerca das práticas e aplicação dos princípios de justiça, bem como da justiça de uma Constituição e de uma legislatura, dentro da concepção da justiça como equidade, Rawls passa a discutir a concepção de liberdade, a qual abarca um grau extenso de liberdade igual compatível para o maior número de pessoas, que ficara, até então, muito abstrata. ${ }^{20}$ Noutros termos, Rawls especifica, através do conceito de liberdade, o que, através da sequência de quatro estágios, estabelecera-se como as liberdades básicas.

Está claro que a função primária dos princípios de justiça, que se aplicam inicialmente à estrutura básica da sociedade, é governar a atribuição de direitos e deveres e regular as vantagens econômicas e sociais. ${ }^{21}$ Igualmente, o primeiro princípio é o padrão primário para a convenção constitucional, estágio no qual são determinadas as liberdades de cidadania igual, a saber:

[...] a liberdade política (o direito de votar e ocupar um cargo público) e a liberdade de expressão e reunião; a liberdade de consciência e de pensamento; as liberdades da pessoa, que incluem a proteção contra a opressão psicológica e a agressão física (integridade da pessoa); o direito à propriedade privada e a proteção contra a prisão e a detenção arbitrárias, de acordo com o conceito de estado de direito. ${ }^{22}$

Essas liberdades devem ser incorporadas e protegidas pela Constituição, num regime democrático e constitucional, conforme o estado de direito vigente. Até a especificação das liberdades básicas na fase

\footnotetext{
${ }^{20}$ É premente a ciência de que esse aspecto da teoria da justiça como equidade sofreu mudanças significativas em virtude das críticas elaboradas por Hart, que resultou, inicialmente, numa revisão completa em Uma Teoria da Justiça, e posteriormente, no artigo "As Liberdades Básicas e sua Prioridade", mais tarde retomado em O Liberalismo Político. Em breves linhas, as críticas de Hart podem ser assim condensadas: Rawls estabelece, como visto, uma relação de prioridade do primeiro princípio, 0 das liberdades básicas iguais, sobre o segundo princípio, o da diferença, no marco da qual, em havendo conflitos no efetivo exercício daquelas liberdades fundamentais, também é preciso estabelecer prioridades. Na opinião de Hart, o problema coloca-se porque o critério adotado por Rawls não é satisfatório para dar conta no estabelecimento da prioridade das liberdades. Cf. HART, Rawls on liberty and its priority, 230-52, In: DANIELS, Reading Rawls. Nova York: Basic Books, 1975. Faz-se aqui a apresentação a partir daquilo que Rawls desenvolveu em $T J$, porquanto ser este 0 objeto da presente investigação.

${ }^{21}$ Cf. RAWLS, $T J, \S 11,64$.

${ }^{22}$ Cf. RAWLS, op. cit., §10, 61; §11, 64-5.
} 
constitucional, as liberdades básicas são altamente abstratas, e serão mais especificamente definidas em termos de liberdades constitucionais, dentro de uma estrutura jurídica inerente à democracia constitucional. ${ }^{23} \mathrm{~A}$ especificação das liberdades definidas pelos princípios de justiça, na ótica da justiça como equidade, são, desse modo, amparadas e protegidas no âmbito de um sistema jurídico, como direitos constitucionais, por meio do estado de direito, que é o resultado da aplicação da justiça formal ao sistema jurídico.

Para Rawls, uma constituição justa faz respeitar o primeiro princípio de justiça, mediante o princípio da participação, o que significa que ela deve conceber o Estado como uma associação de cidadãos em pé de igualdade. Ademais, sendo um caso da justiça procedimental imperfeita, tem dois aspectos, quais sejam ${ }^{24}$ : i) a constituição deve ser um procedimento justo que satisfaz as exigências da liberdade igual; e, ii) a constituição deve ser estruturada de modo que, dentre todas as ordenações viáveis, ela seja a que tem maiores probabilidades de resultar num sistema de legislação justo e eficaz.

Como exposto por Kukathas e Pettit, a liberdade também exige o controle dos poderes do corpo legislativo. Rawls pensa que isso pode ser realizado pelos dispositivos tradicionais do constitucionalismo, a saber: bicameralismo, separação de poderes conjugada com o sistema de freios e contrapesos e uma carta de direitos corretamente aplicada pelos tribunais. ${ }^{25}$

Por isso, uma constituição justa é a que limita os poderes do governo, embora lhe conceda a autoridade para elaborar e fazer cumprir a lei. $\mathrm{O}$ princípio da liberdade exige que haja controle dessa autoridade. Contudo, é desse mesmo princípio que fazemos decorrer a autoridade do governo para impor sanções aos que infringem a lei, já que um governo ineficaz não é capaz de agir de modo a defender liberdades importantes. ${ }^{26}$ Assim, conquanto se tenha presente o modo como uma liberdade igual é menos extensiva, Rawls afirma que ela pode ser reduzida através dos recursos inerentes ao constitucionalismo:

Os recursos tradicionais do constitucionalismo - legislativo bicameral, separação de poderes combinada com equilíbrio e

\footnotetext{
${ }^{23}$ Ver FREEMAN, op. cit., 209-10.

${ }^{24}$ Cf. RAWLS, op. cit., § 14, 91-2.

${ }^{25}$ Cf. KUKATHAS \& PETTIT, op. cit., 67.

${ }^{26}$ Cf. KUKATHAS \& PETTIT, op. cit., 67.
} 
controles, uma declaração de direitos com apreciação judicial - limitam a abrangência do princípio da participação. Suponho, porém, que essas ordenações são consistentes com a liberdade política igual, desde que as restrições semelhantes se apliquem a todos e que os limites introduzidos tendam com o tempo a atingir igualmente todos os setores da sociedade. ${ }^{27}$

À luz disso, é patente que, dentre os principais critérios utilizáveis no julgamento da atuação de um representante e das razões que ele apresenta para justificá-las, encontram-se os princípios de justiça. Uma vez que a constituição é o fundamento da estrutura social, o mais elevado sistema de normas que regula e controla outras instituições, como em certo sentido, também Kelsen a havia descrito, Rawls estatui que todos os cidadãos têm o mesmo acesso ao procedimento político que ela estabelece, pois quando o princípio da participação é efetivamente obedecido, o status comum da cidadania igual fica assegurado. ${ }^{28}$

De fato, pode-se dizer que as liberdades que se encerram na liberdade política igual, tal qual Rawls a conceitua, não são apenas um meio: elas, reforçando nos cidadãos o senso de seu próprio valor, ampliando suas sensibilidades intelectuais e morais, lançam a base de uma noção de dever e de obrigação - no marco do dever natural de justiça e do princípio da equidade -, crucial para que as principais instituições sociais justas, entre as quais o direito, sejam efetivamente estáveis.

\section{Sistema Jurídico: 0 Direito como Instituição}

O sistema jurídico - como uma instituição vinculada ao Estado, organizado de um modo tal que mantenha a ordem pública - é derivado da função que tem o Estado de zelar pela equidade através da mantença das condições indispensáveis para que os indivíduos possam perseguir seus interesses e cumprir com suas obrigações, tal como as entenda por si mesmo. ${ }^{29}$

A caracterização de Rawls do sistema jurídico coloca-se no lastreio da discussão desenvolvida na primeira parte e metade do século XX concernente

\footnotetext{
${ }^{27}$ Cf. RAWLS, TJ, § 36, 245.

${ }^{28}$ Cf. RAWLS, op. cit., § $36,248$.

${ }^{29}$ Cf. NAVARRO, Solidariedad Liberal - La Proposta de John Rawls, 23.
} 
à teoria do direito, matizada, por um lado, no positivismo jurídico, vertente na qual se alinha, de certo modo, Weber e sua análise do conceito de legalidade, assim como as figuras mais expressamente representativas como Kelsen, e, posteriormente, Hart, numa linha da filosofia analítica do direito; e, por outro, na teoria jurídica de Fuller, ferrenho opositor do positivismo e defensor de um jusnaturalismo processual. ${ }^{30}$

Do ponto de vista institucional, Rawls aceita a relativa autonomia do direito enquanto um sistema de regras, na linha de Hart, cuja função primordial e critério de legitimidade fundamental é dado por sua eventual eficiência e funcionalidade. ${ }^{31}$ Essa conceituação do direito, vinculada à definição de justiça formal, é válida para qualquer concepção de sistema jurídico, independentemente de sua vinculação com a justiça como equidade. Trata-se, pois, de um conceito com certa neutralidade sobre o direito tendo em vista que seus preceitos são os que seriam seguidos por qualquer sistema de regras que incorporasse perfeitamente a idéia de um sistema jurídico. ${ }^{32}$ Todavia, para Rawls, o conteúdo do direito deve ser determinado não como para Hart, que o materializa no que chama de um direito natural mínimo, mas assumido intuitivamente, em idêntica forma a como faz o jusnaturalismo fundamentalista, a saber, em princípios de justiça, os quais são definidos através de um procedimento caracterizado pelo consenso, o qual garante em sua estrutura a autonomia das partes e a pretensão de universalidade dos conteúdos. São os princípios da justiça que, ao assumirem o papel da justiça na distribuição de direitos e deveres numa sociedade bemordenada, haverão de definir a justiça substantiva, a qual, no entendimento de Fuller, sempre anda unida à justiça formal. ${ }^{33}$

O direito, enquanto sistema e ordem jurídica, é, segundo Rawls, um conjunto de regras públicas, destinadas a pessoas racionais, para sua

30 Cf. MEJIA QUINTANA, La Problematica lusfilosófica de la Obediencia al Derecho y la Justificacion Constitucional de la Desobediencia Civil, 173-85.

${ }^{31}$ Cf. RAWLS, op. cit., $\S 38,257-66$. Ver também: MEJIA QUINTANA, op. cit., 177.

${ }^{32}$ Cf. RAWLS, TJ, § 38, 258.

33 Para Weber, é certo que as instituições, entre elas o sistema jurídico e, neste, especialmente a Constituição, precisa de princípios orientadores e reguladores. "Regras normativas precisam ser justificadas, caso contrário, ficam arbitrárias. Leis fundamentam-se em princípios que, por sua vez, devem incluir ou contemplar os direitos e liberdades fundamentais. Têm, portanto, uma dimensão ética. Ou seja, quando falamos da justificação de leis, reportamo-nos a princípios e, quando fundamentamos princípios, estabelecemos valores e, quando falamos de valores, que na sua aplicação requerem regularidade e coerência, tratamos de questões éticas." Cf. WEBER, Ética, Direitos Fundamentais e Obediência à Constituição, In: VERITAS, Porto Alegre, v. 51 n. 1, Março 2006, 96-7. 
orientação, permitindo o estabelecimento de bases seguras para expectativas legítimas. As regras que se aplicam às instituições básicas da sociedade são igualmente aplicadas ao direito, enquanto sistema público de regras. Para isso, é primordial acentuar que os princípios de justiça, que orientam a atribuição de direitos e deveres, bem como determinam a distribuição dos benefícios e encargos da vida social, são primariamente destinados à estrutura básica da sociedade tendo em conta sua organização em um esquema de cooperação. ${ }^{34} \mathrm{~A}$ instituição, nesse contexto, é definida como um sistema público de regras, abarcando, pois, desse modo, o sistema jurídico. ${ }^{35}$

Assim sendo, "o sistema jurídico é uma ordem coercitiva de normas públicas destinadas a pessoas racionais, com o propósito de regular sua conduta e prover a estrutura da cooperação social." ${ }^{36}$ Quando essas regras são justas, afirma o autor, elas estabelecem uma base para expectativas legítimas e constituem as bases que possibilitam que as pessoas confiem umas nas outras e reclamem, com razão, quando não vêem suas expectativas satisfeitas. Num sistema de cooperação social, é pertinente e, até certo ponto, necessário que cada uma das partes cumpra a sua parte no esquema geral, o que, de fato, permite que se estabeleça uma base segura para a confiança mútua e para as expectativas legítimas. Desse modo, portanto, pode-se concluir que:

Se as bases dessas reivindicações forem incertas, incertos também serão os limites das liberdades dos homens. [...] Pressupondo-se que essas regras são equitativas ou justas, então, basta que um grupo de indivíduos se filie a essas organizações e aceite os benefícios daí resultantes, para que as obrigações decorrentes constituam as bases para expectativas legítimas. 37

\footnotetext{
${ }^{34}$ É notável o modo como Rawls administra, no âmbito do sistema jurídico, a relação entre direito e moral. Rawls, e outros pensadores contemporâneos, como Dworkin e Habermas, reinserem certos aspectos de moralidade no direito. No caso de Rawls, isso significa dizer que o direito deve ser norteado pelos princípios de justiça, os quais, mediante a administração regular da justiça, fazem surgir o estado de direito, cuja função precípua é a proteção das liberdades básicas - o que, sob certa via, permite afirmar que o fundamento do direito é, do mesmo modo que para Kant, a liberdade. Cf. RAWLS, TJ, § $35,240$.

${ }^{35}$ Cf. RAWLS, op. cit., § 10, 57.

${ }^{36}$ Cf. RAWLS, op. cit., § 38, 257.

${ }^{37}$ Cf. RAWLS, op. cit., § 38, 258.
} 
Seguramente, nesta conjuntura, quando essas regras são justas, elas estabelecem uma base para expectativas legítimas. Ao contrário, se as bases dessas reivindicações forem incertas, ou duvidosas, os limites das liberdades individuais também o serão. Esse aspecto reflete o fundo liberal do pensamento de Rawls. Nesse sentido, se é livre para fazer o que a lei permite: a lei é o espaço da liberdade porque ela é dada pela liberdade.

$\mathrm{O}$ que distingue um sistema jurídico de outros conjuntos de normas públicas endereçadas a pessoas racionais é sua extensão e abrangência e seus poderes regulares em relação às demais associações da sociedade. Neste sentido, Rawls admoesta que os

[...] organismos constitucionais definidos por esse sistema geralmente têm o monopólio do direito legal de exercer pelo menos as formas mais extremas de coerção. Os tipos de coação que as associações privadas podem empregar são rigorosamente limitados. Além disso, a ordem jurídica exerce uma autoridade final sobre certos territórios bem definidos. Ela é também marcada pela extensa gama de atividades que regula e pela natureza fundamental dos interesses que se destina a assegurar. Essas características simplesmente refletem o fato de que a lei define a estrutura básica no âmbito da qual se dá o exercício de todas as outras atividades. ${ }^{38}$

O sistema jurídico tem, então, institucionalmente, o monopólio do direito legal de exercer as formas mais extremas da coação, circunscrita a um determinado território, definição esta que se enfileira no lastro de alguns teóricos, entre os quais, Weber, que definia o direito como o monopólio da coação e da violência, dentro de um determinado território. ${ }^{39}$ Além disso, a ordem jurídica caracteriza-se pela extensa gama de atividades que regula e pela natureza fundamental dos interesses que se destina a assegurar. Noutros termos, a ordem jurídica tem o poder de regular as demais instituições sociais haja vista a extensão de atividades que regula conjugada aos interesses por ela assegurados.

É notório que, embora guiado por princípios de justiça, que são morais, estabelecendo, por conseguinte, a sua validade, o direito é uma esfera

${ }^{38}$ Cf. RAWLS, op. cit., § 38, 258.

${ }^{39} \mathrm{Cf}$. WEBER, Economia e Sociedade, §2, 526. 
que é guiada por regras de sua própria estrutura, ainda que norteado por princípios de justiça. Ao ser considerado que uma lei injusta permanece uma lei válida, apesar de sua injustiça, compreende-se melhor que o direito é responsável por reconhecer, mediante critérios, certos requisitos que conferem validade. Assim, o direito estabelece seus próprios requisitos formais de validade que, em determinadas circunstâncias, podem admitir a existência de ordenações legais injustas.

\section{A Justiça Formal}

Rawls assinala a distinção entre o que chama de justiça substantiva e justiça formal ${ }^{40}$, sendo a última a adesão a princípios. Quanto à justiça formal ${ }^{41}$, Dutra afirma que

$\mathrm{Na}$ formulação de Rawls, quando uma certa concepção de justiça assume o papel da justiça, definindo direitos e deveres fundamentais, determinando a distribuição de recursos e oportunidades e é aplicada imparcial e consistentemente, temse, então, a justiça formal. A justiça formal, assim, independe de princípios substantivos. Ela é aplicada igualmente, mesmo que seus princípios substantivos possam ser injustos, como em um sistema discriminatório. Essa igualdade está implicada na própria noção de direito. Cabe observar que mesmo essa justiça exclui formas significantes de injustiça, pois, através da imparcialidade exigida, ela assegura a segurança. Mesmo com leis injustas é melhor que elas sejam consistentemente aplicadas, pois é melhor do que a arbitrariedade. ${ }^{42}$

Rawls sugere a utilização da terminologia justiça como regularidade ao invés de justiça formal. Trata-se, pois, de uma identificação evidente com a

\footnotetext{
${ }^{40}$ Fuller desenvolveu uma perspectiva congruente entre justiça substantiva e justiça formal. Quanto a isso, para esse autor, "a justiça substantiva e a formal caminhavam juntas, pois regras injustas dificilmente seriam aplicadas imparcial e consistentemente, pois a vagueza das leis deixaria espaço para a arbitrariedade no caso particular. Portanto, onde o Estado de Direito é respeitado e há segurança jurídica, igualmente se encontra justiça substantiva, ou seja, reconhecimento de direitos e liberdade dos outros e distribuição equitativa de bens." Cf. DUTRA, op. cit., 135-6.

${ }^{41}$ Opta-se por manter a utilização da terminologia justiça formal, ao invés de justiça como regularidade sugerida pelo próprio Rawls -, em virtude de que, no âmbito jurídico, a terminologia justiça formal ser mais freqüente e traduzir muitas questões vinculadas ao direito.
}

${ }^{42}$ Cf. DUTRA, op. cit., 135. 
finalidade desta, tendo em vista que justiça como regularidade traduz melhor a idéia de que é uma administração imparcial, guiada senão por regras. Regularidade, portanto, traduz mais adequadamente essa idéia.

Entretanto, nesse contexto, o sistema jurídico institucionalmente é um sistema público de regras destinado às pessoas racionais para sua orientação, estabelecendo, por conseguinte, bases seguras para as expectativas legítimas. A lei, como uma de suas regras, é concebida, pois, como uma diretriz endereçada a pessoas racionais tendo em vista que estabelece e precisa a liberdade para agir. Institucionalmente, suas regras devem satisfazer os princípios de justiça - que assumiram o papel da justiça, como uma concepção de justiça, de tal forma que fornecem uma atribuição de direitos e deveres fundamentais, bem como determinam a divisão das vantagens advindas da cooperação social.

Para Perelman, assim como para Sidgwick, a justiça formal sugere a todos inevitavelmente uma noção de igualdade, que, como já ilustraram Platão e Aristóteles, passando por Santo Tomás e pelos juristas, moralistas e filósofos contemporâneos, alcança certo consenso. Assim, a idéia de justiça consiste numa certa aplicação da idéia de igualdade. ${ }^{43}$

Conforme salienta Rawls, do fato de as leis e as instituições serem igualmente executadas, do tratar casos semelhantes de modo similar, não se segue a garantia de não se incorrer em injustiças, pois isso não basta para assegurar a justiça substantiva. A justiça substantiva, segundo Rawls deixa entender, depende dos princípios de acordo com os quais a estrutura básica de uma sociedade é montada. Assim, a justiça substantiva depende dos princípios de justiça, definidos, no caso de Rawls, na posição original.

No entanto, ocorre que a justiça formal exclui tipos significativos de injustiça que impediriam violações severas dos princípios de justiça, tendo em vista que ao se supor que as instituições sejam razoavelmente justas tem-se que é de grande importância que as autoridades devam ser imparciais e não submetam à influência de considerações pessoais, monetárias ou quaisquer outras irrelevantes, ao lidarem com casos particulares. No caso das instituições legais, a justiça formal é um aspecto do estado de direito que tem por corolário apoiar e assegurar expectativas legítimas, e como tal, deve evitar a injustiça.

${ }^{43}$ Cf. PERELMAN, Ética e Direito, 14. 
A despeito da relação entre a justiça substantiva e a justiça formal, principalmente no que tange à injustiça de leis e instituições, tendo em vista o impedimento de arbitrariedades, Rawls recebe forte influência de Fuller, pois, ao afirmar que alguns dizem que "na verdade a justiça formal e a justiça substantiva tendem a caminhar juntas, e portanto, pelo menos grosso modo, as instituições injustas nunca, ou pelo menos raramente, são administradas de forma consistente e imparciap" 44 , Rawls está justamente remetendo-se a este autor. De fato, Fuller desenvolveu uma perspectiva congruente entre justiça substantiva e justiça formal. Quanto a isso, Dutra assevera que, para esse autor,

[...] a justiça substantiva e a formal caminhavam juntas, pois regras injustas dificilmente seriam aplicadas imparcial e consistentemente, pois a vagueza das leis deixaria espaço para a arbitrariedade no caso particular. Portanto, onde o Estado de Direito é respeitado e há segurança jurídica, igualmente se encontra justiça substantiva, ou seja, reconhecimento de direitos e liberdade dos outros e distribuição equitativa de bens. ${ }^{45}$

Embora inicialmente Rawls apontasse para uma certa reticência em relação à afirmação do entrelaçamento da justiça substantiva com a justiça formal, isso se dava porque àquela altura não havia ainda a determinação dos princípios razoáveis da justiça substantiva bem como as condições em que os homens os escolhem e vivem de acordo com eles. Uma vez que na posição original escolhem-se esses princípios é possível estabelecer os vínculos entre a justiça substantiva e a justiça formal. Certo é que o conteúdo dos princípios da justiça determina a justiça substantiva. E, assim, a justiça formal atua na administração imparcial do que preceitua estes princípios. Quando a justiça formal é aplicada ao sistema jurídico surge o estado de direito.

\section{Estado de Direito}

O estado de direito é, então, o resultado da aplicação ao sistema jurídico da concepção formal da justiça. ${ }^{46}$ Este estado de direito, no entender de Rawls, está intimamente relacionado com a liberdade, visto que esta

\footnotetext{
${ }^{44}$ Cf. RAWLS, op. cit., § 10, 59.

${ }^{45}$ Cf. DUTRA, op. cit., 135-6.

${ }^{46}$ Cf. RAWLS, TJ, § 38, 257.
} 
relação é evidenciada quando se considera a noção de sistema jurídico e de sua íntima conexão com os preceitos que definem a justiça formal, ou seja, o intento do autor é apontar para a perspectiva de que os direitos individuais, especialmente a prioridade da liberdade, são o objeto primário de proteção do estado de direito.

Notoriamente, essa concepção de estado de direito, forjada nas fileiras do kantismo, permite, pois, estabelecer a forma do direito que, grosso modo, é correspondente, preservadas as devidas particularidades, ao conceito de legalidade weberiano, isto é, ao monopólio legítimo da coação. ${ }^{47}$ Assim sendo, a legalidade, característica fundamental do estado de direito, que é o resultado da aplicação da justiça formal ao sistema jurídico, é o que determina a forma do direito, na teoria de Rawls. Portanto, a forma do Direito kantiana, em Rawls, é dada pelo conceito de estado de direito, que pode ser também entendido como a legalidade, haja vista ser a legalidade uma das características do estado de direito.

Desse modo, é permitido dizer que os preceitos do estado de direito são, inequivocamente, qualificações do sistema jurídico na teoria rawlsiana, através do qual se divisa a forma do direito. Evidentemente, para Rawls, existe uma íntima relação entre o estado de direito e a liberdade expressada, sobretudo, quando se considera o sistema jurídico e a profunda conexão com os preceitos que definem a justiça formal - justiça como regularidade. Uma vez que se entenda, decerto, que o sistema jurídico é um sistema de normas públicas dirigidas a pessoas racionais, segundo Rawls, pode-se explicar e explicitar os princípios da justiça associados aos preceitos que definem o estado de direito, os quais, enfatiza Rawls, "são os que seriam seguidos por qualquer sistema de regras que incorporasse perfeitamente a idéia de um sistema jurídico." 48

Certamente, esse é um aspecto relevante a ser considerado, não se espera e nem equivale a dizer que as leis concretas necessariamente satisfazem esses preceitos em todos os casos, pois, aqui, encontra-se não mais na teoria ideal, mas a teoria não-ideal, na qual a sociedade concreta encontra imperfeições. Trata-se, pois, de uma sociedade quase justa, que difere daquela sociedade bem-ordenada, da teoria ideal, na qual não ocorrem violações severas dos princípios da justiça e todos cumprem com a sua fração na

\footnotetext{
${ }^{47}$ Cf. DUTRA, op. cit., 135.

${ }^{48}$ Cf. RAWLS, op. cit., § 38, 258.
} 
cooperação social. Nesse sentido, porque esses preceitos derivam de uma noção ideal, espera-se que as leis aproximem-se deles, senão em todos os casos, pelo menos na maioria das vezes.

Inversamente, se os desvios em relação à justiça formal forem muito difundidos, é permissível, afirma Rawls, questionar e indagar se de fato o que se tem é um sistema jurídico e não apenas uma coleção de ordens particulares da qual a finalidade é a proteção e a promoção dos interesses de um ditador ou o ideal de um déspota benevolente. Essa é uma questão séria porque tem em conta que o presente estado de direto, alinhado a um sistema jurídico, é destinado a uma sociedade democrática, constitucionalmente amparada. Embora Rawls argumente que, para essa questão, não existe uma resposta clara, ele, contudo, afirma que a razão de se pensar numa ordem jurídica como sistema de normas públicas está no fato de que essa condição permite deduzir os preceitos associados com o estado de direito, os quais, numa sociedade democrático-constitucional, podem também denominados de princípio da legalidade.

Ora, pode-se dizer que, em circunstâncias iguais, uma ordem jurídica é administrada justamente, mais que qualquer outra, se ela satisfizer mais perfeitamente os preceitos do estado de direito, isto é, ela será tanto mais justa quanto mais de acordo com a legalidade ela estiver. A legalidade, nesse caso, é uma característica do sistema jurídico que surge, como visto, quando se lhe aplica a justiça formal - justiça como regularidade. Assim sendo, Rawls afirma que o estado de direito fornecerá

[...] uma base mais segura para a liberdade e um meio mais eficaz de organizar esquemas de cooperação. Todavia, pelo fato de garantirem apenas a administração imparcial e regular das regras, independentemente do que venham a ser, esses preceitos são compatíveis com a injustiça. Impõem limites tanto vagos à estrutura básica, mas limites que não são de modo algum desprezíveis. ${ }^{49}$

Dimana, então, que o estado de direito limita a estrutura básica da sociedade de tal forma a dirimir a injustiça e a aplicação desigual da lei e dos estatutos jurídicos de um modo geral, tendo em vista a proteção dos direitos

${ }^{49}$ Cf. RAWLS, op. cit., § 38, 259. 
individuais. No trato dado a esta temática, Rawls postula os seguintes preceitos como pertencendo ao estado de direito: i) o preceito dever implica poder; ii) o preceito casos semelhantes devem receber tratamentos semelhantes; iii) o preceito de que não há ofensa sem lei e iv) os princípios da justiça natural. Estes preceitos são válidos como regras e princípios para o sistema jurídico, que, de certo modo, regula as demais instituições da estrutura básica da sociedade. Assim, são diretrizes que garantem a legalidade da ordem jurídica.

No que se refere ao primeiro preceito elencado, qual seja, o princípio segundo o qual dever implica poder, Rawls argumenta que ele faz emergir algumas características elementares do sistema jurídico, a saber: i) de acordo com a primeira delas, as ações exigidas ou proibidas pelo estado de direito devem ser do tipo que seja razoável supor que os homens podem fazer ou evitar. Assim deve ser porque um sistema de regras destinadas a pessoas racionais para organizar sua conduta deve estar preocupado com o que essas pessoas podem ou não fazer. De fato, Rawls sustenta que um sistema jurídico não deve impor um dever de fazer o que não é possível fazer; ii) a segunda característica, evidenciada na idéia de que o dever implica poder, transmite a idéia de que aqueles que estabelecem as leis e dão ordens fazem-no de boa-fé. Segundo Rawls, leis e ordens são aceitas como tais apenas se existe a crença de que podem ser obedecidas e executadas, pois, "[...] Se houver dúvidas quanto a isso, é de se presumir que as ações das autoridades têm algum outro propósito que não o de organizar a conduta dos cidadãos" ${ }^{50}$; iii) a terceira característica expressa, segundo Rawls, a exigência de que um sistema jurídico deve reconhecer a impossibilidade de execução e obediência de uma norma como uma defesa, ou pelo menos, caso não o possa, que seja considerado como um atenuante. A razão para tal é a de que, ao impor regras, "um sistema jurídico não pode considerar a incapacidade para a execução como algo irrelevante" ${ }^{51}$, posto que, contrariamente, seria "um fardo insuportável para a liberdade se a possibilidade de sofrer sanções não se limitasse normalmente a atos cuja execução ou não-execução está em nosso poder." 52

O estado de direito é, ainda, envolvido pelo preceito da isonomia, ou seja, o de que casos semelhantes devem receber tratamento semelhante. Para

\footnotetext{
50 Cf. RAWLS, op. cit., § 38, 259.

${ }^{51}$ Cf. RAWLS, op. cit., § 38, 259-60.

52 Cf. RAWLS, op. cit., § 38, 259-60.
} 
Rawls, a importância deste preceito está no fato de que, sem ele, as pessoas não poderiam regular suas ações por meio de regras. Assim posto, esse preceito força as autoridades legais "a fundamentar as distinções que fazem entre pessoas, mediante uma referência aos princípios e regras legais pertinentes." ${ }^{3}$ Sob este aspecto, este preceito, do sistema jurídico coloca em relevo a coerência, valendo esta para todas as regras e para as justificativas em todos os níveis. ${ }^{54}$

O estado de direito, assim como o sistema jurídico, é determinado ainda pelo preceito da legalidade, expresso na noção de que não há ofensa sem lei (Nullum crimen sine lege). Segundo Rawls, do ordenamento jurídico, espera-se as seguintes ações: i) que as leis sejam conhecidas e expressamente promulgadas; ii) que seu significado seja claramente definido; iii) que os estatutos sejam genéricos tanto na forma quanto na intenção e que não sejam usados como um meio de prejudicar determinados indivíduos que podem ser expressamente nomeados (decretos confiscatórios); iv) que infrações mais graves sejam interpretadas estritamente; v) que as leis penais não sejam retroativas em detretimento daqueles aos quais se aplicam.

De acordo com Rawls, estas exigências do preceito de que não há ofensa sem lei estão todas implícitas na noção de regulamentação do comportamento por normas públicas, uma vez que,

[...] se, por exemplo, as leis forem claras em suas injunções e proibições, o cidadão não sabe como se comportar. Além disso, embora possa haver ocasionalmente normas confiscatórias ou retroativas, elas não podem constituir características comuns ou típicas do sistema, caso contrário conclui-se que ele tem outro propósito. Um tirano pode mudar uma lei sem aviso prévio, e conseqüentemente punir (se é que essa é a palavra correta) seus súditos, porque sente prazer em ver quanto tempo eles levam para descobrir, mediante a observação das penalidades que lhes são infringidas, quais são as novas regras. Essas regras, porém, não constituiriam um sistema jurídico, uma vez que não serviriam

${ }^{53}$ Cf. RAWLS, op. cit., § 38, 260.

${ }^{54}$ Cf. RAWLS, op. cit., § 38, 260. 
para organizar o comportamento social por meio do fornecimento de uma base para expectativas legítimas. ${ }^{55}$

Torna-se claro que, através do preceito da legalidade, o estado de direito como elemento distintivo do sistema jurídico, deve prover e promover, através da regulação social, uma base sólida e segura para as expectativas legítimas, aquelas que são calcadas na cooperação social, que derivam de uma concepção de justiça distributiva, quando cada qual, membro de uma sociedade democrática, cumpre com a sua parte no quinhão social.

Por fim, Rawls argumenta que o estado de direito é, ainda, determinado pelos preceitos que definem a justiça natural, o item iv, apontado acima, os quais devem, dentro do ordenamento legal, assegurar que a ordem jurídica seja imparcial e regularmente mantida. Segundo Rawls, esses preceitos são concebidos para preservar a integridade do processo jurídico. Nesse aspecto, Rawls está seguindo a análise de Hart.

Agindo segundo esses preceitos que definem a justiça natural, Rawls argumenta no sentido de assegurar a proteção da liberdade ao estabelecer que os órgãos penais, dentro do sistema jurídico, devem respeitar o devido processo para a imputação de penas, respeitar todas as normas para averiguação da culpa e do cometimento de uma infração ou qualquer ato delituoso. Uma vez que Rawls afirma, valendo-se de Hart, que essa idéia decorre de um senso de justiça natural tradicional, pode-se remeter aos princípios processuais presentes na cultura jurídica anglosaxã para estabelecer as bases desses preceitos da justiça natural.

De fato, Hart afirma que os preceitos da justiça natural, no âmbito do direito, são também conhecidos como os princípios processuais, como 'audi alteram partem' ou 'ninguém pode ser juiz em causa própria'. Assim, eles afiançam a imparcialidade ou a objetividade, tendo em vista que são concebidos para assegurar que o direito seja aplicado a todos aqueles e só aqueles casos que são semelhantes no aspecto relevante fixado pelo próprio direito. ${ }^{56}$

Ademais, Rawls entende que, "se as leis são diretrizes endereçadas a pessoas racionais para sua orientação, os tribunais devem preocupar-se com a

${ }^{55}$ Cf. RAWLS, op. cit., § 38, 260-1.

${ }^{56}$ Cf. HART, O Conceito de Direito, 175. 
aplicação e imposição dessas regras da maneira apropriada" ${ }^{7}$, posto que, desse modo, estariam agindo de maneira a proteger e garantir os direitos fundamentais dos membros dessa sociedade. É, pois, nesse sentido que se entende que, com base nesses preceitos da justiça natural, "deve haver um esforço escrupuloso para determinar se houve uma infração e para impor a pena correta" 58 , haja vista que seria um fardo insuportável para a liberdade o sofrimento de sanções de modo arbitrário e sem a lisura de um processo íntegro, imparcial e justo. Em resumo, Rawls está a falar de exigências mínimas estabelecidas pelos preceitos da justiça natural, validando todo o procedimento para que o processe possa ser legítimo, imparcial e de acordo com a justiça.

Desse modo, Rawls faz as seguintes distinções, posto que um sistema jurídico deve: i) estabelecer disposições para a condução ordenada de julgamentos e audiências; ii) conter normas quanto às provas, garantindo procedimentos racionais de informação; iii) exigir, por meio do estado de direito, embora haja variações quanto a esses procedimentos, alguma forma de processo devido, isto é: um processo razoavelmente concebido para verificar a verdade, de modo coerente com os outros objetivos do sistema jurídico, para se saber se ocorreu uma violação e em quais circunstâncias. Como ilustração, Rawls dá o seguinte exemplo:

[...] os juízes devem ser independentes e imparciais, e ninguém pode julgar em causa própria. Os julgamentos devem ser justos e abertos, mas não ser influenciados pelo clamor público. Os princípios da justiça natural devem assegurar que a ordem jurídica seja imparcial e regularmente mantida. ${ }^{59}$

Do exemplo dos juízes, pode-se abstrair algumas preciosas implicações para o sistema jurídico. Entre elas, pode-se afirmar que os juízes devem ser independentes e imparciais, jamais podendo, como se observa, julgar em causa própria. Além disso, os julgamentos devem ser justos e abertos, mas não podendo ser influenciados pelo clamor público.

Esses preceitos que definem o estado de direito estão claramente em íntima conexão com a liberdade. Uma vez que se entenda, como foi visto,

\footnotetext{
${ }^{57}$ Cf. RAWLS, TJ, § 38, 261-2.

${ }^{58}$ Cf. RAWLS, op. cit., $\$ 38,261-2$.

${ }^{59}$ Cf. RAWLS, op. cit., §38, 261-2.
} 
que a liberdade é um complexo de direitos e deveres definidos pelas instituições, "as várias liberdades especificam coisas que podemos escolher fazer, pelo que, quando a natureza da liberdade o exige, os outros têm o dever de não interferir." ${ }^{60}$ Dito de outro modo, se uma lei for imprecisa e incerta, nossa liberdade para agir dentro da estrutura básica da sociedade também será imprecisa e incerta, fincando limitado o exercício da liberdade por um temor razoável, e, conseqüentemente, não haverão meios que possibilitem a criação de uma base para expectativas legítimas.

Para que essa instabilidade não ocorra e nem se generalize, Rawls enfatiza que o "papel de uma interpretação pública das leis legítima, apoiada em sanções coletivas, é precisamente o de superar essa instabilidade" 61 , o que, de fato, só efetivamente ocorre por meio de um sistema público de regras em que o governo afasta os motivos para se pensar que os outros não estão observando as regras, isto é, cabe ao ordenamento jurídico o papel dessa interpretação pública legítima das leis. Rawls conclui, então, que é

Por essa razão pura e simples, presume-se que um poder soberano coercitivo seja necessário, mesmo quando numa sociedade bem-ordenada as sanções não sejam severas e talvez nunca precisem ser impostas. Em vez disso, a existência de um aparelho penal eficaz funciona como garantia nas relações entre os homens. ${ }^{62}$

É pela via de um poder soberano coercitivo que, mesmo dentro de uma sociedade bem-ordenada, argumenta-se e justifica-se a existência de um ordenamento jurídico formado por um complexo de regras e normas públicas endereçado a pessoas racionais, vinculado à proteção e garantia da liberdade.

Os cidadãos de uma sociedade bem-ordenada poderiam portar-se de um modo tal que não requisitasse a existência de um sistema jurídico, ou algo que se assemelhasse a ele, em termos institucionais. Contudo, há por parte de Rawls o entendimento de que se um mecanismo coercitivo é necessário, é obviamente essencial definir com precisão a modalidade de suas operações, pois conhecendo aquilo que penaliza, aquilo que proíbe e sabendo

\footnotetext{
${ }^{60}$ Cf. RAWLS, op. cit., §38, 262.

${ }^{61}$ Cf. RAWLS, op. cit., §38, 263.

${ }^{62}$ Cf. RAWLS, op. cit., §38, 263.
} 
que está em seu alcance praticá-lo ou não praticá-lo, os cidadãos podem fazer seus planos de acordo com esta situação. É esse o sentido da afirmação de que um indivíduo "que obedece as normas conhecidas não precisa temer uma violação de sua liberdade." ${ }^{63}$ Evita-se, por meio de tais exigências, uma conotação tirânica materializada no ordenamento jurídico, que seria opressora da liberdade. Daí a importância de deter-se e centrar-se na proteção das liberdades individuais, o ponto de toque com a liberdade por parte do ordenamento jurídico justo, isto é, aquele que é resultado da aplicação da justiça formal, caracterizado pelo estado de direito.

\section{Considerações Finais}

Como conclusão, pode-se arguir que a reflexão em torno do direito, em Rawls, faz necessário ter ciência da discussão desenvolvida na primeira metade do século XX concernente à teoria do direito, matizada, por um lado, no positivismo jurídico, vertente na qual se alinha, de certo modo Weber, assim como as figuras mais expressamente representativas como Kelsen e Hart, e por outro, na teoria jurídica de Fuller, defensor de um jusnaturalismo processual.

O ordenamento jurídico, como conceitua Rawls, é uma ordem coercitiva de normas públicas, cujo objetivo, em primeiro lugar, é regular a conduta de pessoas racionais, ao mesmo tempo em que fomenta a estrutura da cooperação social, e cuja função o vincula à proteção das liberdades básicas individuais, estabelecendo, pois, uma base para expectativas legítimas numa sociedade bem-ordenada. Como uma instituição regulada pelos princípios de justiça, Rawls promove, desse modo, o encontro da justiça substantiva, definida pelos princípios da justiça, que assumem o papel da justiça, com a justiça formal, que encerra o princípio da legalidade. Portanto, quando aplicada ao sistema jurídico, a concepção formal de justiça e a administração regular e imparcial das normas comuns transforma-se no Direito, por meio do estado de direito, que, caracteristicamente, por sua extensão, tem o poder de regular outras instituições.

Como se procurou apresentar, o que distingue um sistema jurídico de outros conjuntos de normas públicas endereçadas a pessoas racionais é a sua extensão e abrangência e seus poderes regulares em relação às associações da

${ }^{63}$ Cf. RAWLS, op. cit., §38, 264. 
sociedade. O sistema jurídico tem, então, institucionalmente, o monopólio do direito legal de exercer as formas mais extremas da coação, circunscrita a um determinado território. Além disso, como visto, a ordem jurídica caracteriza-se pela extensa gama de atividades que regula e pela natureza fundamental dos interesses que se destina a assegurar. Noutros termos, ela tem o poder de regular as demais instituições sociais, haja vista a extensão de atividades que regula conjuminada aos interesses por ela assegurados. A lei, como uma de suas regras, é concebida, pois, como uma diretriz endereçada a pessoas racionais, tendo em vista que estabelece e precisa a liberdade para agir. Institucionalmente, suas regras devem satisfazer os princípios de justiça - que assumiram o papel da justiça, como uma concepção de justiça, de tal forma que fornecem uma atribuição de direitos e deveres fundamentais, bem como determinam a divisão das vantagens advindas da cooperação social.

Com efeito, a concepção de justiça formal rawlsiana aplica-se diretamente às instituições, e não a pessoas - a não ser de modo indireto -, e especialmente nesse caso, às instituições jurídicas, com o objetivo de garantir e assegurar os direitos fundamentais individuais, estabelecidos, definidos e especificados pelos princípios de justiça, mediante o estado direito. $\mathrm{O}$ estado de direito é, então, o resultado da aplicação ao sistema jurídico da concepção formal da justiça, que como Rawls o descreve, está intimamente relacionado com a liberdade, visto que esta relação é evidenciada quando se considera a noção de sistema jurídico e de sua íntima conexão com os preceitos que definem a justiça formal. É permissível dizer que, mediante os preceitos do estado de direito, encontra-se a forma do direito em Rawls.

Tendo em vista assegurar-se a proteção dos direitos individuais no seio de uma sociedade democrática, Rawls postulou os seguintes preceitos como pertencendo ao estado de direito, a saber: i) o preceito dever implica poder; ii) o preceito casos semelhantes devem receber tratamentos semelhantes; iii) o preceito de que não há ofensa sem lei; e iv) os princípios da justiça natural.

Estes preceitos são válidos como regras e princípios para o sistema jurídico, que, de certo modo, regula as demais instituições da estrutura básica da sociedade. Assim, são diretrizes que garantem a legalidade da ordem jurídica. 


\section{REFERÊNCIAS BIBLIOGRÁFICAS}

BARRY, B. La Teoria Liberal de la Justicia: Examen Crítico de las Principales Doctrinas de Teoria de la Justicia de John Rawls.México: Fondo de Cultura Económica, 1993.

DANIELS, N. Reading Rawls: critical studies on Rawls' a theory of justice. Stanford: Stanford University Press, 1989.

DUTRA, D. J. V. Justiça Processual e Substantiva na Filosofia Prática Contemporânea. In: BAVARESO, Agemir \& HOBUSS, João. (Orgs). Filosofia, Justiça e Direito. Pelotas: EDUCAT, 2005. . Manual de Filosofia do Direito. Caxias do Sul: EDUCS, 2008.

A Legalidade como Forma do Estado de Direito. In: Kriterion, Belo Horizonte, $\mathrm{n}^{\circ}$ 109, Jun/2004, p. 57-80.

DWORKIN, Ronald. Justice in Robes. Harvard University Press, Cambridge, USA, 2006. Levando os Direitos a Sério. 2º ed. São Paulo: Martins Fontes, 2007.

FREEMAN, S.. (Ed.) The Cambridge Companion to Rawls. Cambridge University Press: New York, 2003. Rawls. Taylor \& Francis e-Library, 2007.

FULLER, L. The Morality of Law. New Haven: Conn, 1969.

ART, H. L. A. O Conceito de Direito. $3^{\circ}$ ed, Lisboa: Fundação Calouste Gulbenkian, 2001.

Rawls on liberty and its priority. In: DANIELS, N. Reading Rawls. Nova York: Basic Books, 1975, p. 230-52.

KELSEN, Hans. Teoria Pura do Direito. 3ำ ed., São Paulo: Martins Fontes, 1991.

- Teoria Geral do Direito e do Estado. São Paulo: Martins Fontes, 2000. 
KUKATHAS, C. \& PETTIT, P. Rawls: "Uma Teoria da Justiça” e seus Críticos. Gradiva: Lisboa, 1995.

LOIS, Cecília Caballero. Uma Teoria da Constituição: justiça, liberdade e democracia em John Rawls. Florianópolis, 2001. Tese (Doutorado em Direito) - Universidade Federal de Santa Catarina.

LOPES, J. C. Prefácio: Justiça e Direito, In: JESUS, C. F. R.. John Rawls - A Concepção de Ser Humano e a Fundamentação dos Direitos do Homem. Curitiba: Juruá, 2011.

MEJIA QUINTANA, O. La Problemática Iusfilosófica de la Obediencia al Derecho y la Justificación Constitucional de la desobediência Civil. Bogotá: Universidad Nacional de Colombia, 2001.

MERQUIOR, J. G. O Liberalismo - Antigo e Moderno. São Paulo: Editora Nova Fronteira, 1990.

PERELMAN, C. Ética e Direito. São Paulo: Martins Fontes,1996.

RAWLS, J. A Theory of Justice. Cambridge: Harvard University Press, 1971. . Collected Papers. (Org. Samuel Freeman) Cambridge, Mass: Harvard University Press, 1999.

O Liberalismo Político. São Paulo: Ática, 2000.

. Lectures on the History of Polithical Philosophy. (Org. Samuel Freeman), Cambridge, Mass: Harvard University Press, 2007.

. Uma Teoria da Justiça. São Paulo: Martins Fontes, 2002. . Uma Teoria da Justiça. São Paulo: Martins Fontes, 2009.

WEBER, M. Economia e Sociedade: fundamentos da sociologia compreensiva. Vol II. Brasília, DF: UnB, 1999.

WEBER, T. Ética, Direitos Fundamentais e Obediência à Constituição. In: Revista Veritas, Porto Alegre, v. 51 n. 1, 96-111. Março 2006. 